\title{
Trauma, escrita e silêncio em Diário da queda, de Michel Laub, e em $O$ que os cegos estão sonhando?, de Noemi Jaffe
}

Sileyr dos Santos Ribeiro*

Resumo: Ao longo das últimas décadas, a Shoah vem sendo rememorada em obras de diversos autores ao redor de todo o mundo. Na contemporaneidade, destaca-se a abordagem do tema do ponto de vista das histórias individuais. Neste trabalho, analisamos como Michel Laub e Noemi Jaffe articulam trauma, escrita e silêncio na construção de suas obras, a ficção Diário da queda e o diário comentado $O$ que os cegos estão sonhando?, respectivamente. Investigamos como ambos escritores ressignificam a memória de um trauma histórico coletivo - o genocídio hitlerista - à luz da experiência individual.

Palavras-chave: Michel Laub. Noemi Jaffe. Shoah. Trauma.

\begin{abstract}
Over the past few decades, Shoah has been recalled in the works of several authors around the world. In contemporary times, the approach to the theme from the standpoint of individual stories stands out. In the present work, we analyze how Michel Laub and Noemi Jaffe articulate trauma, writing and silence in the construction of their works, the novel Diário da queda and the commented diary $O$ que os cegos estão sonhando?, respectively. We investigate how both writers resignify the memory of a collective historical trauma - the Holocaust - in the light of individual experience.
\end{abstract}

Keywords: Michel Laub. Noemi Jaffe. Shoah. Trauma.

Resumen: Durante las últimas décadas, la Shoah se ha recordado en las obras de varios autores de todo el mundo. En la actualidad, se destaca el abordaje del tema desde el punto de vista de los relatos individuales. En el presente trabajo, analizamos cómo Michel Laub y Noemi Jaffe articulan trauma, escritura y silencio en la construcción de sus obras, la novela Diário da queda y el diario comentado $O$ que os cegos estão sonhando?, respectivamente. Investigamos cómo ambos escritores resignifican la memoria de un trauma histórico colectivo - el Holocausto - a luz de la experiencia individual.

Palabras clave: Michel Laub. Noemi Jaffe. Shoah. Trauma.

\footnotetext{
* Doutoranda em Letras pelo Programa de Pós-graduação em Letras da Universidade Federal do Espírito Santo (UFES). Bolsista pela Fundação de Amparo à Pesquisa do Estado do Espírito Santo (FAPES). http://orcid.org/oooo-0002-5084-1663 / sileyrribeiro@hotmail.com
}

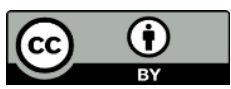


Parte das escritas contemporâneas refletem acerca de eventos de grande impacto traumático e, apropriando-se das temáticas caras à literatura de testemunho, contribuem para a manutenção da memória da barbárie. O testemunho na literatura, ao mesmo tempo em que investiga as narrativas coletivas dos acontecimentos traumáticos, lança o olhar sobre a experiência individual. Seligmann-Silva (2014) atribui ao testemunho um papel preponderante na compreensão do processo histórico, principalmente após a violência extrema do século passado:

Na teoria literária, o conceito de testemunho desempenha um papel central para se entender o processo histórico, com sua violência estrutural, sobretudo a partir do século XX: era tanto de genocídios, guerras e grandes perseguições em massa, como também de afirmação dos direitos humanos. (SELIGMANNSILVA, 2014, p. 8).

Ao longo das últimas décadas, a Shoah - catástrofe em hebraico - vem sendo rememorada em obras de diversos intelectuais ao redor de todo o mundo. Dentre eles, Primo Levi, Paul Celan, Art Spiegelman, W. G. Sebald, Claude Lanzmann, Imre Kertész, Halina Grynberg, Elie Wiesel, Viktor Frankl, dentre outros. Conforme constata Seligmann-Silva (2007), a presença de Auschwitz é "extremamente marginal” nas letras nacionais. No entanto, importantes escritores brasileiros incursionaram pelo tema, como: João Guimarães Rosa, nos chamados “contos alemães” - A senhora dos segredos, A velha e $O$ mau humor de Wotan -, escritos no período em que Rosa foi vice-cônsul em Hamburgo (de 1938 a 1942); Samuel Rawet, nos contos A prece, O Profeta e Réquiem para um solitário, presentes em Contos do Imigrante (1956), seu livro de estreia; e, mais recentemente, Michel Laub, na ficção Diário da queda (2011), e Noemi Jaffe, no diário comentado O que os cegos estão sonhando? com o Diário de Lili Jaffe (1944-1945), de 2012.

Desde o fim da Segunda Guerra Mundial, a recorrência das abordagens sobre o genocídio hitlerista fez com que o tema parecesse esgotado da perspectiva coletiva. Conforme sugere Alice Ferreira (2017), na contemporaneidade, há uma urgência na retomada da Shoah do ponto de vista das histórias individuais, graças, sobretudo, ao reconhecimento de que, "devido às suas singularidades, as gerações seguintes a sentem nessa subjetividade, pois as histórias são suas, particulares” (FERREIRA, 2017, p. 6385). Nas palavras de Jaffe (2012), o registro daquilo que foi vivenciado coletivamente é 
composto por milhares de histórias particulares. Com isso, a Shoah "como experiência individual não se esgota, nem deve se esgotar [...] a vivência coletiva da guerra é uma coleção de memórias individuais" (JAFFE, 2012, p. 185).

De modo similar, o narrador-personagem de Diário da queda aponta uma exploração massiva do Holocausto sob a perspectiva coletiva. Entretanto, ele concebe a experiência individual como um campo nunca totalmente explorado e destaca, assim, a necessidade de o assunto ser trazido à tona justamente por fazer parte de sua própria história: “[...] nem por um segundo me ocorreria repetir essas ideias se elas não fossem, em algum ponto, essenciais para que eu possa também falar do meu avô, e por consequência do meu pai, e por consequência de mim" (LAUB, 2011, p. 9). No presente trabalho, analisamos como Laub (2011) e Jaffe (2012) articulam trauma, escrita e silêncio na construção de suas obras, Diário da queda e $O$ que os cegos estão sonhando?, respectivamente. Investigamos como ambos os escritos ressignificam a memória de um trauma histórico coletivo - a Shoah - à luz da experiência individual dos membros de três gerações de famílias judias: avô/avó sobrevivente, filho/filha e neto/neta.

\section{Trauma intergeracional em Diário da queda e O que os cegos estão sonhando?}

Diário da Queda é o quinto romance do premiado escritor gaúcho Michel Laub. Apresentado em forma de diário, o livro é composto por fragmentos divididos em onze capítulos, cujos títulos são assim denominados: "Algumas coisas que sei sobre o meu avô" (composto por fragmentos numerados de 1 a 38), "Algumas coisas que sei sobre o meu pai” (de 1 a 31), "Algumas coisas que sei sobre mim” (de 1 a 31), "Notas 1" (não numeradas), "Mais algumas coisas que sei sobre o meu avô" (de 1 a 22), "Mais algumas coisas que sei sobre o meu pai" (1 a 28), "Mais algumas coisas que sei sobre mim" (1 a 26), “Notas 2" (não numeradas), "Notas 3" (não numeradas), “A queda” (1 a 35) e "O diário" (o mais longo dos capítulos, estendendo-se de 1 a 40).

A obra é construída do ponto de vista de um narrador autodiegético que apresenta, no tempo da enunciação, problemas relacionados ao abuso de álcool e à 
violência subsequente. $\mathrm{O}$ homem de meia-idade retoma episódios de sua adolescência após a descoberta da doença do pai - Alzheimer - e o ultimato de sua terceira esposa para que deixasse de beber, caso contrário, não poderiam ter um filho. O jornalista recorda quando, aos treze anos, ele e outros colegas de origem abastada e membros de uma renomada escola judaica vão ao aniversário de treze anos de João, contra quem executam um atentado previamente planejado. Durante a celebração, os colegas armam uma espécie de "rede de bombeiros", jogam o estudante bolsista para o alto e o desamparam na décima terceira vez. O aluno, pobre e não judeu - gói -, já havia sofrido reiterados episódios de bullying na escola israelita, sem nunca reagir a qualquer deles. Assombrado pela culpa devido à sua participação no atentado, o narrador confessa à coordenadora da escola o caráter premeditado da queda e passa a ser perseguido pelos colegas delatados. Algum tempo depois, o adolescente aproxima-se de João e decide mudar-se, junto com o novo amigo, para uma escola não judaica.

Por meio da retomada da história do avô sobrevivente e do diálogo com a obra $\hat{E}$ isto um homem?, de Primo Levi, o narrador entrelaça o trauma histórico - Auschwitz às suas lembranças juvenis. Assim, ficamos sabendo que, após a libertação, o avô sobrevivente muda-se para Porto Alegre e vive uma vida aparentemente normal: conhece a esposa - com a qual tem um único filho -, casa-se, trabalha como caixeiro viajante e, alguns anos depois, abre a própria loja de máquinas de costura. No entanto, quando o pai do narrador tem apenas catorze anos, o imigrante alemão comete suicídio. Após sua morte, descobriram o que o avô do narrador fazia trancado em seu escritório: elaborava uma série de cadernos em alemão, cujos verbetes fantasiosos e em um tom demasiadamente otimista formam uma espécie de enciclopédia do mundo às avessas. Ao longo de sua vida e em seus escritos, o sobrevivente silencia sobre sua vida pregressa e suas perdas em Auschwitz, os parentes e as pessoas próximas que lá pereceram, incluindo três irmãos, o pai, a mãe, a namorada, ao menos um primo e uma tia.

Para preencher as lacunas deixadas pelo sobrevivente, resta ao pai do narrador apegar-se ao judaísmo e apropriar-se da memória do Holocausto por meio da leitura da obra $E$ isto um homem?. No entanto, o pai do narrador incorpora apenas o caráter persecutório do judaísmo e, ao tentar transmitir ao filho a experiência omitida pelo avô, o discurso repetitivo acerca de Auschwitz e do antissemitismo acaba por distanciá-los 
cada vez mais. Ao comunicar ao pai sobre a mudança de escola, o narrador e o genitor entram em um conflito verbal, o qual culmina em agressões mútuas. Na ocasião, o filho externa de modo violento seu desprezo pela história do avô e por Auschwitz: “e eu olhando para ele fui capaz de repetir dessa vez devagar, olhando nos olhos dele que eu queria que ele enfiasse Auschwitz e o nazismo e o meu avô bem no meio do cu" (LAUB, 2011, p. 49-5o).

Após o desentendimento, o pai revela ao adolescente como foram os últimos dias do avô e a existência do caderno de notas. O garoto, então, passa a respeitar a história do antepassado. O pai, por sua vez, cessa com os discursos repetitivos e aceita as decisões do filho, inclusive, a de estudar em uma escola não judaica. Graças a essa mudança na postura de ambos, o bom relacionamento entre eles é restituído. No trecho a seguir, o narrador conta como foi a descoberta da história do avô e o impacto disso em sua relação com o genitor e com a memória de seu antepassado:

\begin{abstract}
Meu pai falou dos últimos dias do meu avô, e foi o suficiente para eu entender que não deveria mais ser leviano com esse tema. Eu entendi que era algo que deveria respeitar tanto quanto meu pai respeitava meu direito de estudar numa escola nova, e a partir desse acordo tácito a minha relação com ele passou a ser outra: a minha raiva desapareceu naquele dia, e nas semanas seguintes era como se tudo voltasse a ser como antes da queda de João, os jantares, os fins de semana, as conversas em que eu falava pouco e ouvia o que meu pai tinha a dizer agora sem tentar me convencer de nada, sem me condenar por me submeter aos testes de uma escola onde não havia judeus, e ser admitido numa escola onde não havia judeus, e fazer a matrícula e esperar pelo início das aulas numa escola em que eu achava que ninguém falaria sobre judeus, uma história que poderia ter sido congelada ali, esquecida se não voltasse à tona décadas mais tarde, eu já adulto, já tendo saído de casa, já tendo mudado de cidade e me tornado outra pessoa: João, meu avô, Auschwitz e os cadernos, eu só fui pensar em tudo isso de novo quando recebi a notícia da doença do meu pai. (LAUB, 2011, p. 53).
\end{abstract}

De modo similar à ficção laubiana, a obra $O$ que os cegos estão sonhando? com o Diário de Lili Jaffe (1944-1945) (2012), da autora brasileira e crítica literária Noemi Jaffe, é perpassada pelas narrativas e reflexões de três gerações de mulheres que pertencem a uma mesma família judia: da avó, sobrevivente de Auschwitz, Lili Jaffe; da filha e autora da obra, Noemi Jaffe; e, no último trecho, da filha de Noemi e neta de Lili Jaffe, Leda Cartum. Na primeira parte do livro, a autora reproduz a tradução do diário da mãe, Lili Jaffe, o qual foi escrito logo após seu resgate do campo de Bergen-Belsen pela Cruz 
Vermelha e o posterior transporte até a Suécia. Lili tinha dezessete anos e morava na extinta Iugoslávia - atual Sérvia - quando, junto com os pais e o irmão, foi deportada para Auschwitz. No campo de concentração, a sobrevivente perdeu o pai e a mãe, mas ela e o irmão conseguiram sobreviver.

Os eventos descritos no diário de Lili Jaffe - à época, com sobrenome de solteira, Lili Stern - foram vividos entre os anos de 1944 e 1945. Os escritos contemplam as impressões acerca da passagem, da então jovem de dezenove anos, por Auschwitz e Bergen-Belsen. Em seu diário, a sobrevivente descreve parte de sua experiência durante o regime nazista: desde a deportação, o transporte nos comboios, a perda da mãe, o árduo trabalho na cozinha dos campos em que foi prisioneira, até a passagem pelos campos de refugiados, a posterior redescoberta de sua feminilidade, o retorno à cidade natal e o reencontro com o irmão. O diário de Lili Jaffe, cujo texto original em sérvio está atualmente no Museu do Holocausto Yad Vashem, em Israel, foi uma das inspirações que levou sua filha a elaborar a segunda parte da obra, intitulada "O que os cegos estão sonhando?". Além disso, o texto da sobrevivente motivou sua neta, Leda Cartum, a escrever a parte final do livro de Jaffe (2012), nomeada “Aqui, lá”.

Narrado em terceira pessoa pela narradora/escritora Noemi Jaffe, que se assume como "porta-voz" de sua mãe, o segundo trecho da obra é composto por um formato textual múltiplo, repleto de perguntas, assuntos diversos, compilações de textos e de falas de outros sobreviventes, citações da mãe, etc. Nele, Noemi descreve o impacto da experiência traumática em sua vida e na de sua mãe, relatando as impressões acerca da leitura do diário da genitora, do comportamento da sobrevivente e de uma viagem que fizeram juntas a Auschwitz, em 2009. Por meio de tal passagem, temos acesso a alguns aspectos da vida de Lili Jaffe após a imigração para o Brasil, onde, acompanhada por seu marido, trabalhou como costureira com a sogra e teve três filhas. Segundo Noemi, a mãe sempre assumiu uma postura resiliente diante de quaisquer adversidades enfrentadas ao longo da vida. Para a escritora, tal comportamento resulta daquilo que a sobrevivente aprendeu com seu passado: que, permitindo o destino e tendo força de vontade, as pessoas podem aguentar qualquer coisa. Sob o ponto de vista de Noemi, a postura demasiadamente indulgente e esquecida da mãe é sintoma da experiência concentracionária e indica uma forma de "se lembrar ao contrário". 
A terceira e última parte da obra é também a mais breve. Nela, a filha de Noemi e neta de Lili Jaffe, Leda Cartum, reflete sobre a visita a Auschwitz, feita em 2009 com a mãe e a avó, e examina sua própria relação com a história da sobrevivente. Cartum confessa que, para ela, ser neta de uma sobrevivente significa querer retomar a todo instante algo do passado, mesmo que aquilo que passou seja irrecuperável:

Ser neta de sobrevivente é ter uma relação indireta com este sofrimento que possibilitou minha existência [...] talvez esse seja um dos destinos marcados daqueles que descendem dos sobreviventes: a necessidade de recuperar algo que não pode ser recuperado, a constante sensação de estar puxando uma linha cujo anzol não fisgou nada, apesar de pesar muito. (JAFFE, 2012, p. 234-235).

Em Diário da queda e em $O$ que os cegos estão sonhando?, percebemos o impacto de um trauma histórico coletivo - do Holocausto - no presente. No entanto, as obras lidam de maneira distinta com a memória da barbárie e com as implicações do trauma nas atitudes dos sobreviventes. Para o narrador de Diário, a história geral do mundo, a qual "é tão somente um acúmulo de massacres" (LAUB, 2011, p. 133), ratificaria a força irremediável da "inviabilidade da experiência humana em todos os tempos e lugares" (LAUB, 2011, p. 146) e a impotência humana em se desviar de tal destino. No romance laubiano, o narrador se debruça sobre as escolhas éticas tanto de seu antepassado quanto dos demais membros da cadeia geracional e questiona se as atitudes deletérias do avô sobrevivente - a indiferença ao nascimento do filho, o isolamento no escritório e o posterior suicídio - seriam totalmente justificáveis a partir de uma incapacidade de a vítima de um evento traumático conciliar os atos do presente com o horror vivenciado.

Ao longo de Diário da queda, o narrador investiga as influências do passado nas atitudes do presente. Ao contrário do imigrante alemão, o pai do narrador não se torna indiferente ao nascimento do filho, torna-se um bom marido, um bom pai e um bom patrão, mesmo tendo presenciado, aos catorze anos, a manifestação da "inviabilidade... em todos tempos e lugares" - ao se deparar com o pai caído sobre a escrivaninha. Ao equiparar as ações do avô sobrevivente às do pai, o jornalista problematiza se quem entra em contato com a "inviabilidade... em todos os tempos e lugares" deveria ser responsabilizado, como qualquer outra pessoa, pelo que fez ou deixou de fazer. No 
trecho abaixo, o narrador afirma que seria menos doloroso para os descendentes culpar Auschwitz pelas atitudes dos sobreviventes do que julgá-los enquanto pais e maridos:

É mais fácil culpar Auschwitz do que aceitar o que aconteceu com o meu avô. É mais fácil culpar Auschwitz do que se entregar a um exercício penoso, que qualquer criança na situação do meu pai faria: enxergar o meu avô não como vítima, não como um grão de areia submetido à história, o que automaticamente torna meu pai outro grão de areia diante dessa história, e não há nada mais fácil do que sentir até orgulho por ser esse grão, aquele que sobreviveu ao inferno e está entre nós para contar o que viu, como se meu pai fosse o meu avô e meu avô fosse Primo Levi e o testemunho do meu pai e do meu avô fosse o mesmo testemunho de Primo Levi — enxergar meu avô não como vítima, mas como homem e marido e pai, que deve ser julgado como qualquer outro homem e marido e pai. (LAUB, 2011, p. 81).

Na perspectiva do narrador, tal "inviabilidade" poderia ter servido ao pai como uma espécie de justificativa para as piores atitudes. Graças a isso, “[...] ele poderia ter sido o pior patrão e o pior amigo e o pior marido e o pior pai porque aos catorze anos se defrontou com esse conceito, diante do meu avô caído sobre a escrivaninha" (LAUB, 2011, p. 134). Se assim tivesse ocorrido, reflete o narrador, a briga entre eles na ocasião de mudança de escola e as conversas amigáveis que a seguiram; a notícia sobre o Alzheimer e a sensação de responsabilidade do narrador diante da doença paterna, nada disso teria tido significado na relação entre os dois:

[...] e neste momento eu não estaria falando dele porque já o teria julgado desde sempre, e assim como ele em relação ao meu avô eu não teria nada a dizer a seu favor, e assim como ele em relação ao meu avô eu não teria nenhum carinho ou empatia, e jamais teria me sentido como um filho se sente em relação ao pai sem que precise dizer ou explicar coisa alguma. (LAUB, 2011, p. 134).

A discussão entre pai e filho em virtude da troca de escola é o ponto de cesura da obra e da relação entre ambos. Na ocasião, o narrador lembra ao genitor, com a linguagem da qual dispõe aos treze anos, que repetir o sofrimento judaico do passado serve apenas para justificar o injustificável - o fato de o avô ter arruinado a vida do filho adolescente, de ter se matado sem se importar com ele. No excerto a seguir, o narrador afirma que o avô se agarrou a Auschwitz como um "pretexto": 
[...] a um pretexto, o álibi dele, a aura que o tornava uma espécie de mártir, um santo por haver estragado a vida do meu pai embora tenha seguido à risca as previsões das toneladas de páginas e milhares de filmes e infinitas horas de discussões sobre a inviabilidade da experiência humana em todos os tempos e lugares e como terminaram todos os que tiveram contato com ela, mesmo que ela tivesse um nome tão simbólico e acima de qualquer discussão como Auschwitz. (LAUB, 2011, p. 135).

Desse modo, o narrador estabelece como duas as atitudes possíveis mediante o contato com "a inviabilidade... em todos os tempos e lugares". A primeira, a do avô, consiste em ratificar, na própria condição de sobrevivente, a continuidade da tragédia e a impossibilidade de uma sobrevida após a experiência traumática. Já a segunda diz respeito à ruptura com o legado traumático. Embora o pai reconheça as implicações da memória do sofrimento do povo judaico e de seu próprio trauma em sua vida, o lastro do passado não o impede de ter experiências positivas, tampouco serve para justificar uma postura negligente em relação à família. Assim, o pai do narrador mostra que o nascimento do filho fez diferença em sua vida e que tal acontecimento o impediu de sucumbir ao sofrimento herdado. Tal atitude motiva o narrador a se sentir grato e a acreditar na possibilidade de uma boa convivência entre um pai e um filho.

O narrador compara os cadernos de memórias de seu pai, iniciados após a descoberta da doença, aos de seu avô, enquanto textos que partem do contato direto com "a inviabilidade... em todos os tempos e lugares" e refletem um posicionamento diante dela: do avô, imobilizado por isso; do pai, seguindo adiante a despeito de tudo:

As memórias do meu avô podem ser resumidas na frase como o mundo deveria ser, e daria até para dizer que as do meu pai são algo do tipo como as coisas foram de fato, e se ambos são como que textos complementares que partem do mesmo tema, a inviabilidade da experiência humana em todos os tempos e lugares, o meu avô imobilizado por isso, o meu pai conseguindo ir adiante apesar disso, e se é impossível falar sobre os dois sem ter de também firmar uma posição a respeito, o fato é que desde o início escrevo este texto como justificativa para essa posição. (LAUB, 2011, p. 146, grifos do autor).

Destacando sua posição na cadeia geracional, o narrador reflete que, mediante o ultimato da terceira esposa para que parasse de beber, seria fácil e plausível justificar a escolha de continuar bebendo - e a consequente obstinação autodestrutiva - por meio do argumento de um trauma ou de uma predisposição genética para a violência: 
[...] e até receber o ultimato da minha terceira mulher eu seria capaz de repetir as mais variadas explicações para o fato de sempre ter tido esse comportamento, como se fosse algo involuntário, uma predisposição genética ou o resultado de algum tipo de trauma decorrente de tudo o que vivi desde os catorze anos, porque esse discurso possibilita a você justificar qualquer coisa, mesmo as piores, as mais grotescas, as que você deixa para confessar apenas no final de sua argumentação. (LAUB, 2011, p. 139).

Caso procedesse desse modo, o jornalista poderia dizer que todos os seus problemas do presente remontam aos catorze anos - à queda de João e ao início dos episódios de alcoolismo. No entanto, o narrador escreve o diário destinado ao filho - que é também o Diário - como uma "justificativa para essa posição" (LAUB, 2011, p. 146). A decisão de ter um filho é uma forma de deixar para trás “a inviabilidade... em todos os tempos e lugares".

Em $O$ que os cegos estão sonhando?, a autora também reflete sobre o impacto do trauma na atitude dos sobreviventes após a libertação. Nesse sentido, Jaffe (2012) dialoga com a chamada "zona cinzenta" de Levi (1990), na qual, devido à destituição do humano de sua própria humanidade, devido "à diluição do homem no homem” (JAFFE, 2012, p. 111), julgar as ações dos prisioneiros nos campos de concentração pautando-se em um paradigma moral não seria adequado. Descrita em Os afogados e os sobreviventes, a “zona cinzenta” é ambígua e híbrida. Nela, o poder suspende os pressupostos morais e as noções de bem e de mal. Com isso, alguns fatores circunstanciais impelem o oprimido a tornar-se opressor.

Embora os papéis de vítima e de algoz não sejam intercambiáveis, a linha entre opressor e oprimido é tênue quando as torpezas são praticadas em um contexto em que a própria ideia de humanidade foi sufocada e diluída nos homens. Toda a fauna humana descrita por Levi (1990, p. 124), os Kapos, os políticos, aqueles que, por terem algum favorecimento no campo, eram chamados proeminentes "grandes e pequenos, até os Häftlinge indiscriminados e escravos, todos os degraus da hierarquia insensata determinada pelos alemães estão, paradoxalmente, juntos numa única e íntima desolação [...]”. O autor italiano, tentando compreender como o homem, levado principalmente pela fome e pelo frio onipresentes, barganhava a própria dignidade para obter vantagens, cita a "bolsa do campo" como exemplo da flexibilidade moral dos 
campos de concentração. Nela, permutas de toda sorte faziam com que o judeu, a despeito de sua "judeidade", pudesse se destacar como "proeminente" e obter alguma vantagem que, se não a impedisse, ao menos tardasse sua morte. Levi (1990) não julga moralmente o mal praticado por homens na condição de oprimidos, mas sim busca compreender a condição que os impeliu a tais atitudes dentro das situações-limite.

O narrador laubiano, ao resgatar a história do avô, concebe como duas as atitudes possíveis diante do contato com a "inviabilidade... em todos os tempos e lugares": a do avô e a do pai. O jornalista acrescenta que o genitor se apegou à memória do Holocausto como uma desculpa pelo ódio que sentiu do sobrevivente, mas que, ainda assim, conseguiu se desvencilhar do modelo parental e de repetir as atitudes deletérias do antecessor. Assim, o narrador indaga: "É possível odiar um sobrevivente de Auschwitz como meu pai odiou? É permitido sentir esse ódio de forma pura, sem que em nenhum momento se caia na tentação de suavizá-lo por causa de Auschwitz [...]?” (LAUB, 2011, p. 136).

Jaffe (2012), por sua vez, não apenas lança um olhar compreensivo às atitudes dos sobreviventes dentro e fora dos campos de concentração, como também estende a suspensão do juízo moral aos atos posteriores à experiência traumática. Desse modo, a autora afirma que, "quando se passa pela guerra, todas as atitudes posteriores desta pessoa ficam automaticamente justificadas [...]" (JAFFE, 2012, p. 125). Noemi suspende qualquer juízo sobre as atitudes dos sobreviventes. Assim, a escritora problematiza que, embora seja árduo conceber que tudo se justifique pela guerra, “[...] tudo se justifica, sim. Como alguém pode penetrar na moralidade de quem passou pelo campo? Que cobranças morais podem ser feitas desses sobreviventes? Nenhuma?” (JAFFE, 2012, p. 125).

\section{Trauma, escrita e silêncio}

Os narradores das duas obras são escritores que vivem das palavras e que recolhem as ruínas do passado - pela memória dos sobreviventes - e as reconstroem 
literariamente. Em Diário, as três gerações partilham a atividade escrita. Prado (2016) destaca o hibridismo textual que consolida a voz de autores internos à narrativa laubiana: do avô, sobrevivente de Auschwitz, e seu caderno de verbetes; do pai, acometido pelo Alzheimer, e dos cadernos de memórias; por fim, do próprio narrador e seu diário destinado ao filho que vai nascer. Em $O$ que os cegos estão sonhando?, observamos o imperativo de transmissão da experiência traumática à próxima geração por meio da escrita. Embora não tivesse o hábito de escrever, ao ser indagada sobre o porquê de ter feito um diário, Lili Jaffe diz à Noemi que o escreveu para que a filha lesse: "Quando, no processo de criação deste livro, perguntei a ela por que ela quis tanto escrever, ela me respondeu instantaneamente: 'Para que você lesse!”' (JAFFE, 2012, p. 8).

Ao mesmo tempo em que a escrita de Diário da queda e de $O$ que os cegos estão sonhando? funciona como uma forma de manifestação do legado traumático, as obras são perpassadas por algum tipo de mutismo dos sobreviventes. Em Diário, o duplo silenciamento decorre, por parte do avô, tanto pela ausência de menção à Auschwitz e à vida pregressa quanto pelo silenciamento último, o de si mesmo. Já em O que os cegos estão sonhando?, ao observar que a mãe sempre fala acerca da experiência concentracionária do mesmo modo, Noemi deduz uma espécie de "cristalização" da memória da sobrevivente e um silenciamento de quaisquer outros detalhes acerca do ocorrido. A genitora sempre se lembra das mesmas coisas, conforme relata a escritora: “[...] Lendo o diário, a filha percebe que as histórias que ela conta são exatamente aquelas que estão escritas ali.” (JAFFE, 2012, p. 196). Além do mais, o esquecimento quase automático da imigrante sérvia - "o esquecimento é o eixo constitutivo de sua personalidade" (JAFFE, 2012, p. 125) - é visto pela filha como um sintoma de um grande sofrimento daquilo que a mãe não pôde - e talvez nunca possa - perdoar.

Conforme assinala Rodrigues (2016), para o escritor Primo Levi, há um alinhamento entre a violência infligida a um homem e aquela direcionada à sua linguagem. O regime nazista, que preconizava a superioridade étnica do povo alemão, buscava a supremacia em todos os aspectos, inclusive, no linguístico. O nazismo atacava os meios de expressão de suas vítimas e, devido à "comunicação fraturada”, elas encontravam ainda mais dificuldade para a "elaboração do evento traumático por meio da linguagem" (RODRIGUES, 2016, p. 2). Assim como a ficção laubiana, a narrativa de 
Jaffe é marcada pelo uso de uma forma fragmentária que mimetiza o funcionamento da memória fraturada pelo trauma.

Rodrigues (2016) assinala que, no diário de Lili Jaffe, há diversas ocorrências de emudecimento e de obstáculos na recomposição da memória ferida. A sobrevivente escreve: "Tenho dificuldade de escrever o que aconteceu há cinco dias." (JAFFE, 2012, p. 27). Em outros trechos do registro, o relato ocorre de modo fragmentado e reticente. No trecho a seguir, mesmo revelando a sensação de liberdade experienciada após o resgate pela Cruz Vermelha, Lili Jaffe se vale das reticências para mostrar o impacto da memória do trauma que carrega dentro de si: "O ar é agradável; sinto um vento suave como se estivesse me afagando. Não me falta nada; não desejo nada mais belo; tudo me agrada tanto. Mas o que carrego dentro do coração...” (JAFFE, 2012, p. 67).

Em uma das inúmeras tentativas de entender o comportamento da genitora no período pós-libertação, a escritora/narradora afirma que o próprio livro "é só uma tentativa de uma filha conhecer melhor a sua mãe” (JAFFE, 2012, p. 185). Do mesmo modo que o narrador laubiano questiona o impacto de Auschwitz na forma como o avô sobrevivente se mostrou ao filho - "é impossível que esse horror não tenha alguma relação com Auschwitz e que não tenha se refletido na maneira como meu avô sempre se mostrou para o meu pai." (LAUB, 2011, p. 47) -, Noemi indaga se é justo relacionar todas as particularidades da mãe - a pouca relevância aos acidentes domésticos, a resiliência diante das adversidades, a crença na resolução de todas as coisas, a ira diante do desperdício de alimento, dentre outras - como resultado direto do trauma experienciado. A narradora/escritora responde afirmativamente e acrescenta que a experiência concentracionária impactou não apenas as características e comportamentos da mãe, mas também a vida de toda a família. Se, para o/a sobrevivente, não é relevante "destrinchar" tal impacto, nas palavras de Paula (2018, p. 302), para os/as herdeiros/as do trauma, "sondar as frestas dessas memórias, decifrar o silêncio que elas revelam, é a única maneira de encontrar um lugar na família, um lugar no mundo e um lugar no presente”.

\section{Considerações finais}


Levi (1988, p. 8) aponta o relato dos sobreviventes como algo "elementar", uma vez que, após a libertação, testemunhar concorria com outras necessidades incompressíveis por parte dos sobreviventes: “A necessidade de contar 'aos outros', de tornar 'os outros' participantes, alcançou entre nós, antes e depois da libertação, caráter de impulso imediato e violento, até o ponto de competir com outras necessidades elementares.”. De forma similar, Dori Laub (1992), que passou parte da infância em campos de concentração, constata não apenas a dependência entre sobreviver para contar, mas também entre contar para sobreviver. A autora ressalta que o imperativo de contar e de ser ouvido por parte dos sobreviventes tornou-se uma tarefa de vida, a qual é quase sempre acompanhada pela sensação de que não há palavras nem tempo suficientes para articular a estória e captá-la discursivamente.

Tanto Diário da queda quanto O que os cegos estão sonhando? são obras que, voltando-se à ancestralidade, resgatam a memória dos sobreviventes e demonstram as implicações de um trauma histórico de grandes proporções - a Shoah - na vida das vítimas e na vida das gerações posteriores. Diário da queda parte da "inviabilidade da experiência humana em todos os tempos e lugares" e manifesta, por meio do silenciamento do sobrevivente e de seu posterior suicídio, o impacto dos eventos traumáticos na sobrevida das vítimas. No romance laubiano, mesmo que os escritos do avô contemplem verbetes fantasiosos de "como o mundo deveria ser", é graças à leitura do caderno de notas que temos acesso ao desejo de mundo do sobrevivente. Ao contrário desse "mundo às avessas", o mundo "como de fato foi” é o local em que se repete a “inviabilidade... em todos os tempos e lugares" - na Alemanha nazista da década de 1940, no portão de Auschwitz; em Porto Alegre, na escrivaninha da casa do avô e na queda de João.

Em O que os cegos estão sonhando?, por sua vez, a escritora/narradora reproduz o testemunho da sobrevivente por meio do diário de Lili Jaffe, escrito logo após a libertação de Auschwitz e destinado à filha. Diante dos reiterados esquecimentos da mãe e de sua postura demasiadamente indulgente, Noemi percebe uma relação direta com a experiência concentracionária. Ao ser indagada acerca de tudo que passou antes da 
libertação, Lili Jaffe restringe-se a narrar os acontecimentos de forma muito similar àquela descrita no diário. Tal repetição faz com que Noemi perceba a escrita da mãe como uma cristalização do ocorrido, que, condensando a memória do que passou, fez tanto com que a sobrevivente pudesse registrar de algum modo o que viveu, quanto se esquecer dos detalhes daquilo que não pôde perdoar.

Ambas as obras são permeadas pelos escritos dos sobreviventes e por algum tipo de silenciamento. Na ficção laubiana, o avô corporifica um sobrevivente que, a despeito do caráter elementar do testemunho relatado por Levi (1988), abstém-se de contar o que viveu. Já na obra de Jaffe (2012), a escrita da sobrevivente frutifica do imperativo de testemunhar e surge, então, como uma tentativa de compreender e de registrar para as próximas gerações o que aconteceu, mesmo que o trauma não possa ser representado e extrapole a própria capacidade de compreensão da vítima.

\section{Referências}

FERREIRA, Alice Cardoso. Testemunho e pós-memória em Noemi Jaffe e Michel Laub. Anais eletrônicos do XV encontro da Abralic. Rio de Janeiro, 2018. p. 6380-9. Disponível em: <https://abralic.org.br/anais/arquivos/2017 1522178832.pdf> Acesso em: o2 de março de 2021.

JAFFE, Noemi. O que os cegos estão sonhando? com o Diário de Lili Jaffe (1944-1945). São Paulo: Ed. 34, 2012.

LAUB, Dori. An event without a witness: truth, testimony and survival. In: FELMAN, Shoshana (Org.). Testimony: crises of Witnessing in Literature, Psychoanalysis and History. New York: Routledge, 1992. p. 75-90.

LAUB, Michel. Diário da Queda. São Paulo: Companhia das Letras, 2011.

LEVI, Primo. Os afogados e os sobreviventes. Tradução de Luiz Sérgio Henriques. Rio de Janeiro: Paz e Terra, 1990.

. É isto um homem? Tradução de Luigi Del Re. Rio de Janeiro: Rocco, 1988. 
PAULA, Marcelo Ferraz de. O testemunho oblíquo em O que os cegos estão sonhando?, de Noemi Jaffe, e Maus, de Art Spiegelman. Estudos de literatura brasileira contemporânea, Brasília, n. 55, p. 285-308, set./dez. 2018.

PRADO, Rafael Barreto do. Imagens de língua na prosa literária brasileira: as narrativas do século XXI. 2016. 212 f. Tese (Doutorado em Letras) - Universidade de São Paulo, São Paulo, 2016.

RODRIGUES, Breno Fonseca. Memória e testemunho: a fragilidade da narrativa em $O$ que os cegos estão sonhando?, de Noemi Jaffe. Arquivo Maaravi: Revista Digital de Estudos Judaicos da UFMG, Belo Horizonte, v. 10, n. 18, p. 45-59, maio 2016.

SELIGMANN-SILVA, Márcio. Trauma, lei e literatura: o olhar crítico de Shoshana Felman sobre o Direito (Prefácio). In: FELMAN, Shoshana. O inconsciente jurídico: julgamentos e traumas do século XX. Tradução de Ariani Bueno Sudatti. São Paulo: Edipro, 2014. p. 7-13.

- Literatura da Shoah no Brasil. Arquivo Maaravi: Revista Digital de Estudos Judaicos da UFMG, Belo Horizonte, v. 1, n. 1, p. 123-135, out. 2007.

Recebido em 03/03/2021. Aprovado em 17/04/2021. 